\title{
The irruption of Airbnb and its effects on hotel profitability: An analysis of Barcelona's hotel sector
}

\author{
Juan Pedro Aznar ${ }^{1}$ (D), Josep M Sayeras ${ }^{1}$ (D), Alba Rocafort ${ }^{2}$ (D) Jorge Galiana ${ }^{3}$ iD \\ ${ }^{1}$ ESADE Business School (Spain) \\ ${ }^{2}$ Manchester University (United Kindgdom) \\ ${ }^{3}$ EAE Business School (Spain)
}

juanpedro.aznan@esade.edu,josepm.sayeras@esade.edu,_arocafort@rocafortnicolau.com.jorge.galiana.richart@,campus.eae.es

Received October, 2016

Accepted November, 2016

\section{Abstract}

Purpose: The aim of this study is to analyze the existence of a relationship between the presence of nearby substitute products, mainly Airbnb flats or rooms, and the effect on the revenue and profitability of hotels.

Design/methodology: The empirical study is based on the analysis of financial information provided in the annual reports of a sample consisting of 43 hotels (11.78\% of the population). As an explanatory variable for profitability, we have considered the presence of apartments listed in Airbnb that are no farther than one kilometer from each hotel. Considering that most of the variables used do not follow a normal distribution, the existence of a relationship between profitability and the explanatory variables has been tested using non-parametric tests, namely, the Spearman correlation coefficient and Kruskall-Wallis test.

Findings: We found a positive correlation between presence of Airbnb apartments and return on equity. This fact can be explained by considering the presence of Airbnb apartments as a variable that measures the attractiveness of the location from a tourist's point of view. Hotels 
located near the city center or main tourist areas of the city have a higher level of profitability. We also found no evidence of any relationship between profitability and star category; 4- and 3star hotels have experienced, on average, a lower drop in revenues between 2008 and 2013 and they also obtained a higher average level of profitability in 2013 as compared to the upper segment of 5 -star hotels.

Research limitations/implications: This research has been conducted in the city of Barcelona. Future research using the same methodology should be applied to other cities with an important hospitality sector to reinforce our findings. The main implications of this research refer to the importance of location as a key strategic variable in hospitality, and to the change in the system customers use to evaluate the quality of a hotel, according to which the traditional star category system has been partially replaced by new sources of information available through the new communication technologies.

Originality/value: This paper is one of the first contributions that scholars have made to obtain a deeper understanding of the effects of the new forms of the sharing economy, focusing on the hospitality industry.

Keywords: Airbnb, Hospitality profitability, Location, Star category system

Jel Codes: Z30, L83

\section{Introduction}

The sharing economy is a new phenomenon with consequences in many different areas: business profitability and changes in the structure of some industries, new players that force others to revise optimal strategies, changes in consumer behavior, a challenge for governments in deciding how to regulate these activities, and a new way of using information and communication technologies (Hamari, Sjöklint \& Ukkonen, 2015). Some sharing economy platforms are experiencing rapid growth (Schor, 2014), with an impact on traditional sectors, such as the taxi industry, in which Uber is an important new player, and the hospitality industry, in which the rapid expansion of Airbnb is the best-known example. Understanding the real impact of these new forms of consumption on the traditional 
industry is essential in order to define appropriate economic policies and set up an efficient regulatory framework.

The impact of these new platforms is pervasive in the media, but it still requires an in-depth analysis from scholars. One of the cases that has been controversial is the effect of the Uber application on the taxi industry. According to the New York Times (Barro, 2014), the price of a taxi medallion has dropped 17\%, from a peak in the spring of 2013 to October 2014, with the new supply offered by drivers registered on the Uber online platform being an important reason why, according to the taxi industry. In many countries, the taxi industry has filed lawsuits, alleging that Uber represents unfair competition (Muñoz, 2015). It is possible for Uber drivers to avoid paying income tax, they do not pay for a license to operate, and they do not have to follow the regulations of the taxi industry. The effects of these new types of activities work both ways, with some negative effects, but also some positive ones for consumers. Among the positive effects, the most common are an increase in consumer welfare, thanks to new options for consumers, and the pressure to reduce prices. One concern that could be considered the primary negative effect is related to safety. The taxi industry is highly regulated (Feeney \& Companies, 2015), while Uber drivers are not subject to traditional taxi regulations. In Germany, the United States and Spain, courts have ruled by banning Uber services in the interests of consumer safety. The consequences on the labor market are a major concern. Because the service is based on the will of a potential passenger and a driver who freely offers their services, based on this assumption, the drivers are not considered to be Uber employees, so they do not have the worker protection established by labor regulations in most developed countries. The driver may provide services on a part-time basis, but if this is their main activity, they have no protection as a worker under labor laws, because the relationship with the Uber platform is not a labor relationship, rather a relationship regulated under commercial law. The new supply that Uber is generating keeps prices down, but it can also keep wages low in order to obtain larger profit margins, if the employers have any degree of bargaining power.

In this article, we want to focus on a similar platform that has become very popular as an alternative to hotel accommodation: Airbnb. This platform was founded in 2008, and has experienced exponential growth in many cities where tourism is an important economic activity. According to Edelman and Luca (2014), Airbnb was assessed by investors in 2012 to be worth as much as $\$ 2.5$ billion. The importance of this platform is clear if we consider that according to its own website, it is now present in 190 countries, and more than 60 million overnight stays haven been booked using this website since it started to provide services (data from February 2016). Airbnb is a platform on which owners can 
offer a room or an entire dwelling. Each owner listed on Airbnb has a historical record of evaluations by past customers; this information helps reduce the imbalance of information available between the supplier and the potential customer.

The controversy surrounding the Airbnb platform has reached the courts. In October 2013, the Attorney General in New York claimed that Airbnb hosts were violating the New York Multiple Dwelling Law (Jefferson-Jones, 2015). According to the New York Attorney General's Office, in October 2013 72\% of Airbnb New York hosts were breaking the law. Other cities where there has been a debate about whether short-term rentals like those provided by Airbnb are legal are San Francisco, Paris and Barcelona.

Airbnb is affecting the hospitality industry. The hotel industry is characterized by entry barriers, for example, the need for a license and the initial investment. Hotels are characterized by important fixed costs (Aznar \& Sayeras, 2015). The cost structure of these businesses make their profitability vulnerable to any adverse shock in demand, and for that reason, a drop in revenue usually implies a greater reduction in profits. Airbnb is increasing the supply of accommodations by offering a similar, but cheaper alternative, with a structure of new suppliers with no significant fixed costs. The expected effects would be a drop in profitability and a reduction in the capacity by the traditional sector to generate revenue. This is a situation in which there are important differences between the traditional industry and the new players.

The aim of this paper is to analyze whether hotel revenues, and therefore profitability, are affected by the fact that they are surrounded by a huge supply of Airbnb hosts. The data used refers to a sample of hotels in the city of Barcelona, one of the most important city destinations for tourists in Europe. The structure of the paper is as follows: Section 2 contains the literature review, Section 3 describes the sample and the main statistics, Section 4 discusses the statistical tests used in order to evaluate our hypothesis, and finally the last section summarizes our conclusions and makes recommendations regarding future lines of research. 


\section{Literature review}

Tourism activities have become key activities in many regions and cities. The demand in the hospitality industry is highly dependent on the demand shocks caused by a range of many different possible factors, from natural catastrophes and political instability to changing economic conditions, such as recessions or high volatility in the exchange rate (Ryu, Bordelon \& Pearlman, 2013). The profitability of this industry is strongly dependent on revenue changes caused by changes in demand or the increase in supply. Zervas, Proserpio and Byers (2015) argue that hotels are characterized by the importance of fixed costs in their cost structure and a lower marginal cost. Considering these characteristics, a reduction in revenues usually implies a greater reduction in net income. The emergence of Airbnb hosts in 34,000 cities, with millions of overnight stays per year can be considered an important shock to the demand in the hospitality industry in some cities.

The profitability of this industry depends on many factors, some external and others internal. Sainaghi (2010) has reviewed the academic literature, summarizing the main explanatory factors in the profitability of hospitality that have been considered. Most of the studies use internal factors as explanatory variables for hotel performance. According to Brander Brown and McDonnell (1995), most managers rely on financial indicators when they evaluate business performance, although there is an increasing use of other non-financial indicators. In the sample of papers published in the international journals analyzed by Sainaghi (2010), 83\% of empirical studies use internal factors as the dependent variables to explain hotel performance, and just $9 \%$ use external variables, with the number of papers that mix internal and external ones being a minority.

Some efforts have been made towards understanding which financial variables can be predictors of a better financial performance. Hua, Nusar and Upneja (2012) used a logit model with a sample of 410 publicly traded lodging establishments, relying on observations from 1970 to 2008. The factors they identify that explain why a hotel outperforms the sector include size, considering that economies of scale are a characteristic of the lodging industry; a lower leverage ratio, which makes the net income more flexible in the presence of unexpected negative revenue shocks; and being a member of a franchise, as an aspect with positive implications for profitability.

In the service sector, the quality of service provided has become one of the most relevant variables. This is why customer-oriented strategies are more efficient than other alternatives, as Grissemann, Plank and Brunner-Sperdin (2013) have shown in their research. Kim, Cho and Brymer (2013) checked some hypotheses regarding explanatory factors of better performance; the empirical study was based 
on a sample of 95 hotels from 65 cities in United States. The accepted conclusions were that hotel size was positively correlated with the average daily rate (ADR), and a positive relationship was found between customer satisfaction and ADR. The hotel type was also a significant variable, with customer satisfaction depending on whether the hotel was a resort or a hotel oriented towards business travelers.

Yu and Huiming (2005) found evidence of a relationship between financial performance, the star rating system and being operated as independent hotels or belonging to international chains. Hotels ranked as 4- or 5-star have higher revenue per available room (RevPAR) than lower categories of hotels, and the gap was also favorable to hotels managed by international chains. Naragajavana and $\mathrm{Hu}(2008)$ studied the star rating and hotel performance for a sample of 306 hotels in Thailand; most hotels that applied for consideration under the star system were interested in the 3- to 5-star categories, with just a few wanting to apply for lower categories. However, it is not clear whether the star rating system is a good indicator of quality (Fernández \& Bedia, 2004).

The effect that the new forms of sharing economy, with Airbnb listings being the most popular website platform, have on the profitability of the hospitality industry is a new topic for scholars. The most frequently cited work at the moment is the empirical research published by Zervas et al. (2015). They analyzed the impact of an increase in Airbnb listings in the most important cities in the state of Texas. They used a regression model that considered the change in revenue for the hotels dependent on how many dwellings and apartments were listed on Airbnb. The regression model also included variables affecting the sector, such as the supply of rooms, economic growth, evolution of employment and a variable for temporary shocks affecting the hospitality industry in the state of Texas. Two main conclusions were reached. The first was significant, from a statistical point of view: the effect of Airbnb on the profitability of the hospitality sector. An increase of $1 \%$ in the listings from Airbnb implies a reduction of $0.05 \%$ in hotel revenues. The second conclusion was that this effect was greater for low-category hotels.

Based on the previous literature, the hypotheses to be tested are:

Hypothesis 1: Profitability is negatively affected by a major presence of nearby apartments.

Hypothesis 2: Profitability is positively affected by the size of the hotel.

Hypothesis 3: Profitability is positively affected by the star rating of the hotel. 


\section{Data}

Two different sources of information have been used. The INE (Instituto National de Estadistica, the Spanish statistics office) provides valuable information about how supply and demand have changed over the last few years. We have also used information from the annual reports of the individual hotels that are part of our sample. The individual hotel information was gathered from the SABI (Sociedad de Análisis de Balances Ibéricos) database. All the firms considered have accommodation services as their main activity, and they are registered as hotels. They are located in Barcelona, and were actively operating as of the date of the study. We also checked certain information, namely location and star category, on their websites.

The sample consists of 43 hotels in the city of Barcelona. In 2015, Barcelona had 365 hotels; we have used a sample that represents $11.78 \%$ of the total population, and its structure in terms of star category is very similar to that observed in the population. Table 1 shows the data related to the structure by star category.

\begin{tabular}{|l|r|r|}
\hline \multicolumn{1}{|c|}{ Star category } & \multicolumn{1}{|c|}{ Sample } & Population \\
\hline 1 star & $4.7 \%$ & $9.3 \%$ \\
\hline 2 stars & $11.6 \%$ & $9.9 \%$ \\
\hline 3 stars & $27.9 \%$ & $31.8 \%$ \\
\hline 4 stars & $48.8 \%$ & $41.9 \%$ \\
\hline 5 stars & $7.0 \%$ & $7.1 \%$ \\
\hline
\end{tabular}

Table 1. Sample and population distribution

Airbnb started as a new company in 2008 and rapidly expanded in many cities. To examine profitability with the aim of analyzing how it correlates with the presence of Airbnb, we have used two measures: the difference between revenues from 2008 to 2013 and the return on equity (ROE) according to the available data in the hotels' annual reports. Airbnb is not the only variable affecting the profitability of hotels; in fact, the hospitality industry in Barcelona is very dynamic. From 2008 to 2013, the number of overnight stays, a measure of the change in demand, has increased by $32.37 \%$, with $16,485,074$ overnight stays in 2013. As the supply increased, the number of beds also grew during the same period by $19.61 \%$.Most of the new supply is concentrated in the 3- and 4-star category, rather than the 5-star category, which shows a lower level of profitability. The increase in supply has been consistent with the change in demand, and the occupancy rate has been almost constant, at a value of around $60 \%$. When we consider the average data, the change in revenue experienced by the 43 hotels analyzed saw an 
average decrease of $11.6 \%$. With a constant occupancy rate, the reason behind this drop is a strategy of lowering prices. The average daily rate (ADR) has declined from €142 in 2008 to $€ 115.35$ in 2013, representing an $-18.77 \%$ change. There could be many reasons for this decrease: the pressure from new competitors, apartments and the Airbnb supply of rooms, the change in the willingness of many consumers to pay higher prices in a situation of financial crisis characterized by an important reduction in disposable income, or the competition of other cheaper destinations.

The ROE and changes in revenues experienced according to hotel category fail to show any dependent relationship. According to the literature (Yu \& Huiming, 2005; Narangajavana \& Hu, 2008), profitability is positively affected by the star rating of the hotels. Our data show a different picture, with a better financial performance for 3- or 4-star hotels than the 5-star hotels belonging to the top category. Table 2 shows these results.

\begin{tabular}{|r|r|r|r|}
\hline Star category & Number of hotels & $\begin{array}{c}\text { Average difference in } \\
\text { revenue, 2008-2013 }\end{array}$ & $\begin{array}{c}\text { Return on equity } \\
\mathbf{2 0 1 3}\end{array}$ \\
\hline 2 & 5 & $15.39 \%$ & $10.67 \%$ \\
\hline 3 & 12 & $-1.20 \%$ & $7.57 \%$ \\
\hline 4 & 21 & $-6.46 \%$ & $3.47 \%$ \\
\hline 5 & 3 & $-16.10 \%$ & $3.93 \%$ \\
\hline
\end{tabular}

Table 2. Return on equity and difference in revenue, in terms of the category system

To measure the size of the hotels, two options were considered: the number of employees and the total assets. These data have been considered as reported in the annual financial reports for 2013, the last year available in the database. As an internal variable with effects on profitability, we also take into account the leverage, expressed as the ratio of total debt to total assets, again using the data from the 2013 annual reports. The star category, which was collected from the hotel websites, has been included as a variable with possible implications for profitability. Finally, we were determined to measure the presence of apartments listed on Airbnb. Using the Airbnb website, we counted how many apartments were offered no farther than one kilometer from the hotel.

All the variables showed a high degree of dispersion. Table 3 shows the average, maximum and minimum values for each variable considered. 


\begin{tabular}{|l|r|r|r|r|}
\cline { 2 - 5 } \multicolumn{1}{c|}{} & \multicolumn{1}{c|}{ Mean } & \multicolumn{1}{c|}{ Maximum } & \multicolumn{1}{c|}{ Minimum } & \multicolumn{1}{c|}{ Std. deviation } \\
\hline Number of employees & 52.77 & 316 & 8 & 63.724 \\
\hline Total assets & $€ 14,364,798.58$ & $€ 116,970,676$ & $€ 951,753$ & $€ 20,901,053.55$ \\
\hline Leverage ratio & $39.28 \%$ & $96.22 \%$ & $2.7 \%$ & $30.01 \%$ \\
\hline Number of Airbnb-listed rooms & $1,806.88$ & 3,000 & 0 & 918.12 \\
\hline Return on equity (ROE) & $5.584 \%$ & $27.05 \%$ & $-36.15 \%$ & $13.34 \%$ \\
\hline \% change in revenue 2008-2013 & $-11.60 \%$ & $95.01 \%$ & $-53.10 \%$ & $32.07 \%$ \\
\hline
\end{tabular}

Table 3. Descriptive statistics

In terms of profitability, 10 hotels $(23.26 \%)$ experienced negative profitability in $2013 ; 10$ hotels (23.26\%) showed positive levels of profitability, but below a threshold of $5 \%$; and 12 hotels $(27.91 \%)$ managed a return greater than $10 \%$. These values show a high degree of heterogeneity. The hospitality industry is an economic sector with high differentiation in terms of the quality of service, location, strategy design and targeted market segment and as a result, financial performance measures are highly variable. The fact that a number of hotels have negative profitability is consistent with the existence of exit barriers, an important one being the specificity of the non-current assets used in the activity.

The dynamics of the revenues during the 2008-2013 period shows a scenario in which only $20.93 \%$ of the hotels increased their revenue. Almost $80 \%$ suffered a decrease in revenues, and 7 out of the 43 hotels that make up the sample (16.28\%)saw their revenues fall by more than $25 \%$. Again, this variable has a high degree of dispersion.

\section{Results}

In order to identify the most suitable test to confirm or reject the hypotheses, we tested the normality of the variables. Considering the fact that the size of the sample is 43 , we used the Shapiro-Wilk test. With the exception of return on equity (ROE), the rest of variables do not follow a normal distribution.

To test the first hypothesis, the existence of a negative relationship between the nearby presence of Airbnb apartments and financial performance, we used the Spearman correlation, with the differences in revenues during the 2008-2013 period and there turn on equity in 2013 serving as the measures of financial performance.

In both cases, the coefficient is positive, indicating that a major presence of Airbnb apartments correlates with a lesser decrease in revenue and a better return. However, the coefficient of correlation 
is not statistically significant in the case of revenue, although the positive correlation between the presence of Airbnb lodging and the shareholders' return is significant at a 5\% level. These results possibly indicate how important location is as a strategic variable. A high concentration of Airbnb apartments occurs in the city center and in other main tourist locations. Hotels located in these highvalue areas, from the customers' perspective, have a positive differentiation factor. A good location allows the hotel to charge a higher price and the demand will be probably less elastic than in hotels located far from the city center.

The second hypothesis concerned the existence of a positive correlation when comparing the star rating and there turn on equity. Once again using the Spearman coefficient, the correlation proved to be negative; in fact, 5-star hotels are less profitable than 4- and 3-star establishments, as shown in Table 2. However, once again, the negative correlation is not statistically significant. Therefore, we can conclude that 3- and 4-star hotels have been more profitable and have suffered a lower drop in revenue, but more data are needed to assess whether this effect is statistically significant. Table 4 summarizes the results of the test performed to check Hypotheses 1 and 2.

\begin{tabular}{|l|r|r|l|}
\hline Variables & Spearman coefficient & Significance & \multicolumn{1}{|c|}{ Conclusion } \\
\hline $\begin{array}{l}\text { Airbnb presence and change } \\
\text { in revenue (\%) }\end{array}$ & 0.210 & 0.176 & $\begin{array}{l}\text { The correlation is not } \\
\text { significant }\end{array}$ \\
\hline Airbnb presence and ROE & 0.388 & 0.10 & $\begin{array}{l}\text { The correlation is } \\
\text { significant at a 5\% level }\end{array}$ \\
\hline Size and profitability (ROE) & -0.160 & 0.311 & $\begin{array}{l}\text { The correlation is not } \\
\text { significant }\end{array}$ \\
\hline
\end{tabular}

Table 4. Two-tailed Spearman's correlation test

The third hypothesis refers to the existence of differences in profitability, according to the star category. An intense debate over the meaning of each star category has taken place in the academic literature (Zervas et al., 2015; Yu \& Huiming, 2005). Today, customers have alternatives to measure the quality of a hotel and how it changes at any given moment. The use of websites that allow not only booking the hotel, but also seeing how past customers rated the hotel and their comments has changed the informative role associated with the star category. In fact, in our sample 3- and 4-star category hotels perform better than 5-star establishments in terms of the change in revenue from 2008 to 2013 and the ROE. To determine whether these differences are significant, and considering the non-normal distribution of the variables in our sample, we used a non-parametric test, namely the Kruskal-Wallis 
test. The result obtained is that there are no significant differences among the means value for the return according to the star category of the hotels.

\section{Conclusions}

The progress of the sharing economy is an unstoppable phenomenon in our societies and economic systems. The impact of these new forms of activity not only has economic effects, it also has social ones: they generate an intense debate regarding the fairness of these new forms of competition. Scholars must analyze the new situation in order to obtain greater insight that will help develop optimal economic strategies in terms of welfare. The hotel industry is facing major challenges, but it is fundamental to understand the impact of each variable. The current situation of low returns and decreasing revenues is a consequence of an array of factors: a change in disposable income, new competitors, and also the very dynamics of the industry itself, in which there are more hotels and lower prices. In this scenario, some firms are capable of increasing revenues and obtaining a return that by far outperforms the sector. Future research analysis should focus on trying to figure out what the key factors of profitability are that are common to the hotels that outperform the sector.

This article has a limited geographical scope. Future research focusing on other cities will reinforce or contradict our findings. Our results suggest that location is a key factor in explaining better performance. Being located near to a huge supply of Airbnb apartments is common for hotels in the city center, a location that many customers are willing to pay extra for. On the other hand, it is not clear whether the star rating is still an explanatory variable of profitability. The quality of the service, in a situation where the problem of asymmetric information is partially solved, thanks to the use of new technologies, is a second driver of profitability. But new alternatives are currently emerging, as more efficient ways of measuring the quality of the service are devised that do not rely on the traditional star system.

\section{Acknowledgments}

The authors wish to thank Xavier Camarasa and Inés Losada, research assistants at the ESADE Business and Law School for their important contribution to the creation of the database used to test the hypotheses proposed in this paper. 


\section{References}

Airbnb website. https://es.airbnb.com/s/Barcelona--España. (Last access date: November and December, 2015).

Aznar Alarcón, J., \& Sayeras Maspera, J. (2015). The financial and economic performance of hotels in Spanish beach tourist destinations. Athens Journal of Tourism, 2(3), 141-152.

Barro, J. (2014). Under pressure from Uber, taxi medallion prices are plummeting. The New York Times.

Brander Brown, J., \& Mcdonnell, B. (1995). The balanced score-card: Short-term guest or long-term resident?. International Journal of Contemporary Hospitality Management, 7(2/3), 7-11. https://doi.org/10.1108/09596119510146751

Edelman, B.G., \& Luca, M. (2014). Digital discrimination: The case of Airbnb.com. Harvard Business School NOM Unit Working Paper, (14-054). https://doi.org/10.2139/ssrn.2377353

Feeney, M., \& Companies Uber, R. (2015). Is Ridesharing Safe?. Cato Policy Analysis, 767, 2.

Fernández, M.C.L., \& Bedia, A.M.S. (2004). Is the hotel classification system a good indicator of hotel quality?: An application in Spain. Tourism Management, 25(6), 771-775.

https://doi.org/10.1016/j.tourman.2004.06.007

Grissemann, U., Plank, A., \& Brunner-Sperdin, A. (2013). Enhancing business performance of hotels: The role of innovation and customer orientation. International Journal of Hospitality Management, 33, 347-356. https://doi.org/10.1016/j.ijhm.2012.10.005

Hamari, J., Sjöklint, M., \& Ukkonen, A. (2015). The sharing economy: Why people participate in collaborative consumption. Journal of the Association for Information Science and Technology, 67, 2047-2059. http://doi.org/10.1002/asi.23552

Hua, N., Nusair, K., \& Upneja, A. (2012). Financial characteristics and outperformance: Evidence of a contemporary framework from the US lodging industry. International Journal of Contemporary Hospitality Management, 24(4), 574-593. https://doi.org/10.1108/09596111211226833

INE, Instituto Nacional De Estadística. http://www.ine.es. (Last access date: November 10th, 2015).

Jefferson-Jones, J. (2015). Can Short-Term Rental Arrangements Increase Home Values?: A Case for Airbnb and Other Home Sharing Arrangements. Cornell Real Estate Review, 13(1), 12-19.

Kim, W.G., Cho, M., \& Brymer, R.A. (2013). Determinants affecting comprehensive property-level hotel performance: The moderating role of hotel type. International Journal of Hospitality Management, 34, 404-412. https://doi.org/10.1016/j.ijhm.2012.12.002 
Muñoz, P.J. (2015). Uber ante el tribunal de justicia de la unión europea: La incidencia del recurso a las plataformas en línea en la calificación jurídica de los servicios prestados. Revista Democracia Digital e Governo Eletrônico, 2(13), 111-122.

Narangajavana, Y., \& Hu, B. (2008). The relationship between the hotel rating system, service quality improvement, and hotel performance changes: A canonical analysis of hotels in Thailand. Journal of quality assurance in hospitality \& tourism, 9(1), 34-56. https://doi.org/10.1080/15280080802108259

Ryu, K., Bordelon, B.M., \& Pearlman, D.M. (2013). Destination-image recovery process and visit intentions: Lessons learned from Hurricane Katrina. Journal of Hospitality Marketing \& Management, 22(2), 183-203. https://doi.org/10.1080/19368623.2011.647264

SABI. Database-Bureau Van Dijk. Sistema De Análisis De Balances Ibéricos (System Analysis of Iberian Balances). Retrieved from: https://sabi.bvdinfo.com. (Last access date: November-December, 2015).

Sainaghi, R. (2010). Hotel performance: state of the art. International Journal of Contemporary Hospitality Management, 22(7), 920-952. https://doi.org/10.1108/09596111011066617

Schor, J. (2014). Debating the sharing economy. Great transition initiative, October 2014.

Yu, L., \& Huimin, G. (2005). Hotel reform in China a SWOT analysis. Cornell Hotel and Restaurant Administration Quarterly, 46(2), 153-169. https://doi.org/10.1177/0010880404273892

Zervas, G., Proserpio, D., \& Byers, J.W. (2015). The Impact of the Sharing Economy on the Hotel Industry: Evidence from Airbnb's Entry Into the Texas Market. In Proceedings of the Sixteenth ACM Conference on Economics and Computation (pp. 637-637). ACM. https://doi.org/10.1145/2764468.2764524

Intangible Capital, 2017 (www.intangiblecapital.org)

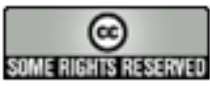

Article's contents are provided on an Attribution-Non Commercial 3.0 Creative commons license. Readers are allowed to copy, distribute and communicate article's contents, provided the author's and Intangible Capital's names are included. It must not be used for commercial purposes. To see the complete license contents, please visit http://creativecommons.org/licenses/by-nc/3.0/. 